\title{
Dubins Path Tracking Controller of USV using Model Predictive Control in Sea Field
}

\author{
${ }^{1,2}$ Tahiyatul Asfihani, ${ }^{2}$ S. Subchan, ${ }^{1}$ Daniel M. Rosyid and ${ }^{3}$ Aries Sulisetyono \\ ${ }^{1}$ Department of Marine Engineering, \\ ${ }^{2}$ Department of Mathematics, \\ ${ }^{3}$ Department of Marine Engineering, \\ ${ }^{3}$ Department of Naval Architecture Engineering, Institut Teknologi Sepuluh Nopember, \\ Surabaya, Indonesia
}

\begin{abstract}
This study considers a USV controller for trajectory tracking. The USV moves along the trajectory at constant forward speed with a measured disturbance. The input for the USV motion is the rudder angle. The USV controller is obtained by using Robust Model Predictive Control. This study considers the sea wave as a disturbance. The trajectory is generated by Dubins path. The computational results show that the robust MPC can guide the ship to follow the trajectory and handle the disturbance. The performance of Robust MPC is similar to the case of MPC when applied to a disturbance-free model.
\end{abstract}

Key words: Dubins path, USV, MPC, wave disturbance, computational results, trajectory

\section{INTRODUCTION}

The Unmanned Surface Vehicle (USV) requires navigation, guidance and control system which able to direct the vehicle to move along the desired point (Subchan and Zbikowski, 2009). Navigation system usually uses Global Positioning System (GPS) which gives the position. The guidance system is a path planning that result in a desired trajectory based on initial and final position from a navigation system. Path planning can be obtained from several methods, one of them is Dubins path (Subchan et al., 2008). The Dubins path is an optimal path that satisfies maximum curvature bound between two points with a particular orientation in a field of both CLC (Circle-Line-Circle) or CCC (Circle-Circle-Circle) path or combination of both where, $\mathrm{C}$ is circle and $\mathrm{L}$ is a line that intersects with C (Tsourdos et al., 2010). The Dubins path has several advantages and require only an initial point, a final point, an orientation and a minimum turning radius (Putri and Asfihani, 2018). Besides that, the Dubins path generate the trajectory without consuming a lot of CPU-time which is more optimal and efficient (Sorbo, 2013).

The main problems of a USV controller are trajectory tracking and path following (Encarnacao and Pascoal, 2001). The task of designing ship controller for trajectory tracking is very challenging, especially, in autopilot mode. Recently, many papers studied a control to obtain more accurate trajectory tracking (Yin and Xiao, 2017;
Sonnenburg and Woolsey, 2012; Dong et al., 2015). Trajectory tracking control aims at forcing a vehicle to converge and follow the desired trajectory (Do and Pan, 2009).

Encarnacao and Pascoal proposed the coupling of trajectory tracking and path following (Encarnacao and Pascoal, 2001). By Peng et al. (2007) a line of sight projection algorithm for minimization of the crosstrack error to the path is considered. The basis is a $3 \mathrm{DOF}$ (surge, sway, yaw) ship maneuvering model. The controls in surge and yaw are obtained using backstepping. The design technique is robust, since, the integral action can easily be implemented. Note that the controller also can be utilized for a fully actuated ship, since, the control law is derived without assuming a specific control allocation scheme.

The Model Predictive Control (MPC) method is a popular method for a trajectory tracking control and applicable for industries (Qin and Badgwell, 2003). This type of control is included in the category of a ControllerBased Process Model by minimizing a criterion function (Camacho and Bordons, 1999). Moreover, MPC can also combine all the objectives into a single objective function. The MPC method for trajectory tracking control was considered By Zheng et al. (2014, 2018), Guerreiro et al. (2014). In reality, when the ship is sailing on a sea there are environment disturbances such as wave, wind and ocean current (Fossen, 2011). Therefore, the ship requires a robust controller where the controller can handle a

Corresponding Author: Tahiyatul Asfihani, Department of Mathematics, Institut Teknologi Sepuluh Nopember, Surabaya, Indonesia 


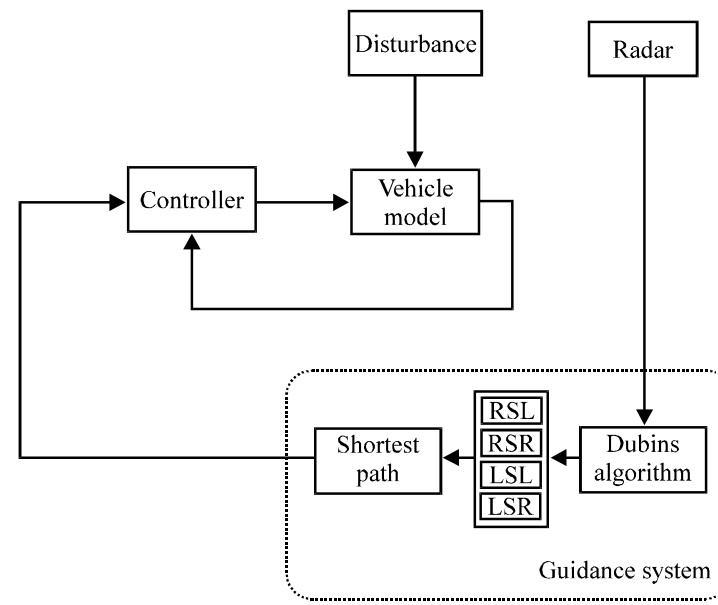

Fig. 1: The scope of this researcher

disturbance (Mayne, 2014). Robust MPC are studied by many researchers (Subchan et al., 2014; Li and Sun, 2012; Li et al., 2010; Wang et al., 2011). An existence of environmental disturbances is one of the factors that motivate this research to propose Disturbance Compensating-Model Predictive Control (DC-MPC) on USV. The DC-MPC is a modification of MPC where there are some additional steps: estimating the disturbance and optimizing the control compensating caused by disturbance. The disturbance in this problem is assumed to be measured (Li and Sun, 2012).

The MPC and DC-MPC are model-based control algorithm which require mathematical model of ship motion and a kinematic model. This study employe a linear model of ship with 2 DOF (sway and yaw). Our model is derived from the David and Schiff model by assuming that the surge velocity is constant (Fossen, 1994).

The scope of this research is shown in Fig. 1. The main contribution of this study is design robust controller for the USV when tracking the optimal Dubins path. This problem is solved using MPC and DC-MPC. This research gives an alternative method which is better than previous ones in controlling the surface vehicle by calculating natural disturbance. In addition, it can be used in ship control design. The steps of this research are as follows. First, we generate a path using Dubins path algorithm. Then we determine the trajectory tracking controller of USV using MPC and DC-MPC. The mathematical model of USV is based on error model.

\section{MATERIALS AND METHODS}

Mathematical model of ship motion: The kinematics model of ship are as follows (Yin and Xiao, 2017):

$$
\begin{aligned}
& \dot{\mathrm{x}}=\mathrm{u}_{0} \operatorname{Cos} \psi-\mathrm{v} \operatorname{Sin} \psi \\
& \dot{\mathrm{y}}=\mathrm{u}_{0} \operatorname{Sin} \psi+\mathrm{v} \operatorname{Cos} \psi \\
& \psi=\mathrm{r}
\end{aligned}
$$

The objective of trajectory tracking is a ship heading angle $(\psi)$ towards a desired heading angle $\left(\psi_{\mathrm{d}}\right)$ where $\psi_{\alpha}$ is obtained from Dubins path. A ship motion has $6^{\circ}$ of freedom (DOF), that are surge, sway, yaw, roll, heave, pitch. In this study, we use a mathematical model of ship motion on 2 DOF, i.e., sway and yaw. The mathematical model of ship motion is based on linear model by Davidson and Schiff (1994) where surge velocity is constant (Asfihani et al., 2017):

$$
\mathrm{M} \dot{\mu}+\mathrm{N}\left(\mathrm{u}_{0}\right) \mu=\mathrm{b} \delta_{\mathrm{R}}
$$

Where:

$$
\begin{aligned}
& \mu=[\mathrm{v}, \mathrm{r}]^{\mathrm{T}}, \mathrm{v}=\text { Sway velocity } \\
& \mathrm{r}=\text { Yaw velocity } \\
& \mathrm{u}_{0} \quad=\text { Surge velocity } \\
& \delta_{\mathrm{R}} \quad=\text { Rudder angle } \\
& \mathrm{M}=\left[\begin{array}{cc}
\mathrm{m}-\mathrm{Y}_{\mathrm{v}} & \mathrm{mx}_{\mathrm{G}}-\mathrm{Y}_{\mathrm{r}} \\
\mathrm{mx}_{\mathrm{G}}-\mathrm{N}_{\mathrm{v}} & \mathrm{I}_{\mathrm{z}}-\mathrm{N}_{\mathrm{r}}
\end{array}\right] \\
& \mathrm{N}\left(\mathrm{u}_{\mathrm{o}}\right)=\left[\begin{array}{cc}
-\mathrm{Y}_{\mathrm{v}} & \mathrm{mu}_{\mathrm{o}}-\mathrm{Y}_{\mathrm{r}} \\
-\mathrm{N}_{\mathrm{v}} & \mathrm{mx}_{\mathrm{G}} \mathrm{u}_{0}-\mathrm{N}_{\mathrm{r}}
\end{array}\right] \\
& \mathrm{b}=\left[\begin{array}{c}
\mathrm{Y}_{8} \\
\mathrm{~N}_{8}
\end{array}\right]
\end{aligned}
$$

Notice that $Y_{w}, Y_{v}, N_{v}, N_{r}$ are added mass, $Y_{w}, Y_{r}, Y_{8}, N_{r}$, $\mathrm{N}_{8}$ are hydrodynamic coefficients, $\mathrm{m}$ is mass of the ship, $\mathrm{x}_{\mathrm{G}}$ is its center of gravity. Added mass and hydrodynamic coefficients are obtained from strip theory (Fossen, 1994). From Eq. 1, we obtain the following state-space Eq. 2:

$$
\dot{\mu}=\mathrm{A}_{1} \mu+\mathrm{B}_{1} \mathrm{u}
$$

where, $u=\delta_{R}, A_{1}=-M^{-1} N\left(u_{0}\right)$ and $B_{1}=M^{-1} b$. This study focus on trajectory tracking, so, we construct the error model of heading angle and position. The objective of the Dubins path tracking is that the error model of heading angle and position converge to zero. The error model of heading angle $\left(\psi_{\mathrm{e}}\right)$ is obtained from a heading angle of the ship $(\psi)$ and a Dubins 


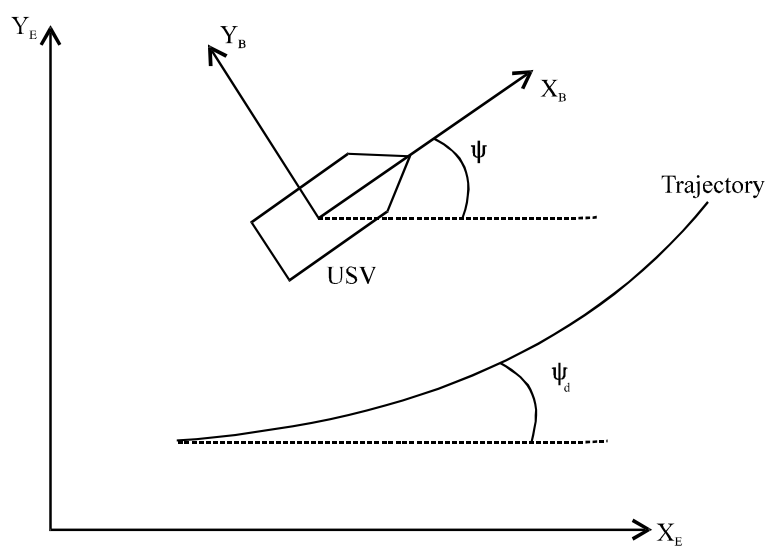

Fig. 2: USV motion

path angle $\left(\psi_{d}\right)$ (Fig. 2). The error heading angle can be modeled by $\psi_{\mathrm{e}}(\mathrm{t})=\psi(\mathrm{t})-\psi_{\mathrm{d}}(\mathrm{t})$. So, we have Eq. 2 :

$$
\dot{\psi}_{e}(t)=\dot{\psi}(t)-\dot{\psi}_{d}(t)=r(t)-\dot{\psi}_{d}(t)
$$

The position error $\left(Z_{e}\right)$ is obtained from kinematics model of ship and assumed that $x_{e}$ is constant. So, the error model of position can be obtained as follow:

$$
\dot{\mathrm{Z}}_{\mathrm{e}}=\mathrm{u}_{\mathrm{o}} \sin \psi_{\mathrm{e}}+\mathrm{v} \cos \psi_{\mathrm{e}}
$$

Based on the dimension of the USV (Sulisetyono and Putranto, 2017), the mathematical model of the USV is given by Eq. 2 where:

$$
\begin{gathered}
A_{1}=\left[\begin{array}{cc}
-0.6137 & -0.1018 \\
-5.0967 & -3.4086
\end{array}\right] \\
B_{1}\left[\begin{array}{l}
0.01 \\
1
\end{array}\right]
\end{gathered}
$$

The mathematical model of the USV motion when tracking the path is given below:

$$
\dot{\mathrm{x}}=\mathrm{f}\left(\mathrm{x}, \mathrm{u}, \dot{\psi}_{\mathrm{d}}\right)
$$

where, $x=\left[v, r, \psi_{e}, Z_{e}\right]^{T}$ and $f$ from Eq. 2-4. The mathematical model of Eq. 5 is nonlinear system. Linear form of Eq. 5 is obtained as:

$$
\dot{\mathrm{x}}=\mathrm{Ax}-\mathrm{S}+\mathrm{Bu}
$$

Where:

$$
\begin{aligned}
A & =\left[\begin{array}{cccc}
-0.6137 & -0.1018 & 0 & 0 \\
-5.0967 & -3.4086 & 0 & 0 \\
0 & 1 & 0 & 0 \\
1 & 0 & 8.32111 & 0
\end{array}\right] \\
\mathrm{S} & =\left[\begin{array}{c}
0 \\
0 \\
\dot{\psi}_{\mathrm{d}} \\
0
\end{array}\right] \\
\mathrm{B} & =\left[\begin{array}{c}
0.01 \\
1 \\
0 \\
0
\end{array}\right]
\end{aligned}
$$

The discrete linear system is obtained from Eq. 6 using forward difference equation where:

and

$$
\mathrm{x}=\frac{\mathrm{x}(\mathrm{k}+1)-\mathrm{x}(\mathrm{k})}{\Delta \mathrm{t}}
$$

$$
\psi_{\mathrm{d}}=\frac{\psi_{\mathrm{d}}(\mathrm{k}+1)-\psi_{\mathrm{d}}(\mathrm{k})}{\Delta \mathrm{t}}
$$

The discrete linear system is given as follow:

$$
\mathrm{x}(\mathrm{k}+1)=\mathrm{A}_{\mathrm{d}} \mathrm{x}(\mathrm{k})-\mathrm{S}_{\mathrm{d}}(\mathrm{k})+\mathrm{B}_{\mathrm{d}} \mathrm{u}(\mathrm{k})
$$

Where:

$$
\begin{array}{ll}
\mathrm{A}_{\mathrm{d}} & =\mathrm{I}+\Delta \mathrm{tA} \\
\mathrm{I} & =\text { Identity matrix } \\
\Delta \mathrm{t} & =\text { Sampling time } \\
\mathrm{x}(\mathrm{k}+1) & =\text { State at time } \mathrm{k}+1 \\
\mathrm{~B}_{\mathrm{d}} & =\Delta \mathrm{tB}:
\end{array}
$$

$$
\mathrm{S}_{\mathrm{d}}(\mathrm{k})=\left[\begin{array}{c}
0 \\
0 \\
\frac{\psi_{\mathrm{d}}(\mathrm{k}+1)-\psi_{\mathrm{d}}(\mathrm{k})}{\Delta \mathrm{t}} \\
0
\end{array}\right]
$$

$\psi_{\mathrm{d}}(\mathrm{k})$ is orientation of Dubins path at time $\mathrm{k}$. A constraint of a yaw velocity is $|\mathrm{r}| \leq 0.0932$, a rudder angle is $|\mathrm{u}| \leq 35^{\circ}$ and a rudder rate limit is $|\Delta \mathrm{u}| \leq 5^{\circ} \mathrm{sec}^{-1}$.

Dubins path: The Dubins path is a shortest path consisting of arc circles and straight lines. The following input parameters are required to design the Dubins path (Tsourdos et al., 2010):

- Start position of $\operatorname{ship} \mathrm{P}_{\mathrm{S}}\left(\mathrm{x}_{\mathrm{s}}, \mathrm{y}_{\mathrm{s}}, \psi_{\mathrm{s}}\right)$

- Final position of a ship $\mathrm{P}_{\mathrm{f}}\left(\mathrm{x}_{\mathrm{f}}, \mathrm{y}_{\mathrm{f}}, \psi_{\mathrm{f}}\right)$ 


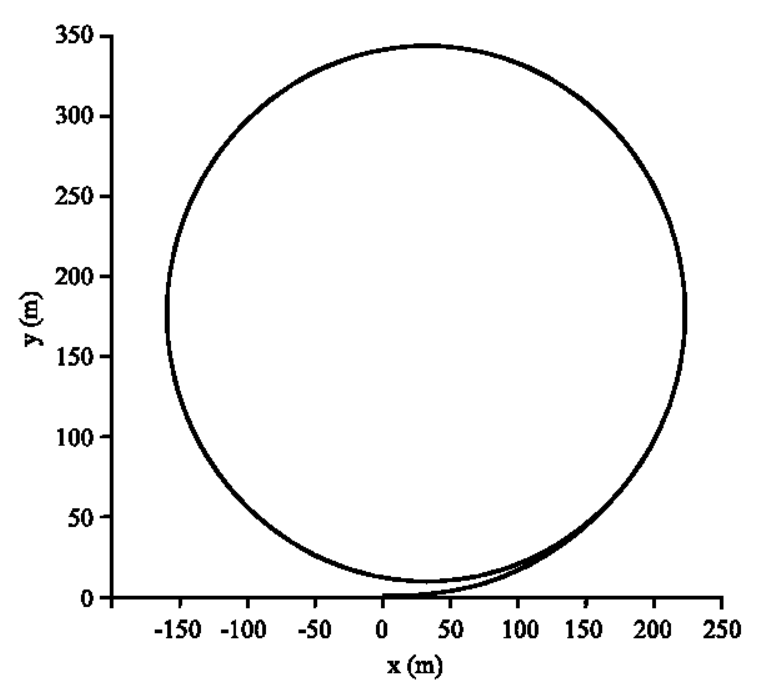

Fig. 3: The turning test of the ship by the maximum rudder angle $\left(35^{\circ}\right)$

- Radius of start curvature is $\left(k_{s} \leq k_{\max }\right)$ is $\rho_{s}$

- Radius of final curvature is $\left(\mathrm{k}_{\mathrm{fs}} \leq \mathrm{k}_{\max }\right)$ is $\rho_{\mathrm{f}}$

The Dubins path ((q)) can be represented by,

$$
P_{S}\left(x_{s}, y_{s}, \psi_{s}\right) \rightarrow r(q)\left(x_{f}, y_{f}, \psi_{f}\right),|k(t)| \leq k_{\max }
$$

By inputing the four parameters, the Dubins path algorithm produces the possible Dubins paths. Clasification of the possible Dubins paths are LSL (Left-Straight-Left), RSR (Right-Straight-Right), LSR (Left-Straight-Right) and RSL (Rright-Straight-Left). The shortest path of the four possible paths is the desired Dubins path.

The turning radius of the ship is obtained based on a turning test. The turning test is performed by turning the vehicle over at maximum speed with maximum rudder angle. The minimum turning radius can be obtained from simulation of mathematical model with constant rudder angle. We obtain a minimum turning radius of USV $188 \mathrm{~m}$ (Fig. 3).

Model predictive control for Dubins path tracking: The MPC controller requires an objective function. The objective function of this research is the ship can follow the Dubins path when there is a wave sea disturbance, i.e., the models error go to zero. The error models are output systems (Eq. 6). The design of the controller MPC will be represented below:

$$
\begin{aligned}
& \min _{\mathrm{T}}(\mathrm{u}(\cdot \mid \mathrm{k})) \mathrm{J}=\sum_{\downarrow(\mathrm{i}=1)} \uparrow_{\left(\mathrm{N}_{\downarrow} \mathrm{p}\right)}\left[\mathrm{y}(|\mathrm{k}+\mathrm{i}| \mathrm{k})^{\uparrow} \mathrm{T}\right. \\
& \mathrm{Q}_{\downarrow \text { iy }}(\mathrm{k}+\mathrm{i} \mid \mathrm{k})+\mathrm{u}+(\mathrm{k}+\mathrm{i}-1 \mid \mathrm{k}) \uparrow_{\mathrm{TR}} \uparrow_{\mathrm{iu}}(\mathrm{k}+\mathrm{i}-1 \mid \mathrm{k})
\end{aligned}
$$

Subject to:

$$
\begin{gathered}
x(k+j \mid k)=A_{d} x(k+j-1 \mid k)+B_{d} u(k+j-1 \mid k)-S_{d}(k+j-1 \mid k)+d(k) \\
C_{1} x(k+j \mid k) \leq D_{1}, j=1, \ldots, N_{p} \\
P u(k+j-1 \mid k) \leq T \\
P \Delta u(k+j-1 \mid k) \leq V \\
d(k) \in D
\end{gathered}
$$

where, $y(k), x(k), u(k), d(k)$ are the output systems, the state systems, the controller, the wave sea disturbance, respectively, at time t. The constraint in Eq. 9 represent the prediction model using a discrete form of mathematical model in Eq. 7 and a disturbance and the constraints in Eq. 10-12 for state and input control, respectively. $N_{P}$ and $\mathrm{N}_{\mathrm{C}}$ are prediction horizon and control horizon, respectively. The number starts from zero until the determined number where $N_{p} \geq N_{C}$. In this study, $N_{p}=N_{C}$ $x(k+j \mid k)$ and $u(k+j \mid k)$ are the state and control, respectively, $\mathrm{j}$ steps ahead of the current time $\mathrm{k}$ and $\mathrm{x}(\mathrm{k} \mid \mathrm{k}=\mathrm{x}(\mathrm{k}))$. The output system is $y(k)=C x(k)$ where, $x(k)$ is a variables system in Eq. 6. Lets

$$
\mathrm{Y}=[\mathrm{y}(\mathrm{k}+1 \mid \mathrm{k}) \mathrm{y}(\mathrm{k}+2 \mid \mathrm{k}), \ldots, \mathrm{y}(\mathrm{k}+\mathrm{NP} \mid \mathrm{k})] \mathrm{T}
$$

we obtain:

$$
\mathrm{Y}=\mathrm{Fx}(\mathrm{k})+\theta \overline{\mathrm{u}}+\mathrm{G} \overline{\mathrm{S}}
$$

where, $\overline{\mathrm{u}}=\left[\mathrm{u}(\mathrm{k} \mid \mathrm{k}) \mathrm{u}(\mathrm{k}+1 \mid \mathrm{k}) \mathrm{u}(\mathrm{k}+2 \mid \mathrm{k}), \ldots, \mathrm{u}\left(\mathrm{k}+\mathrm{N}_{\mathrm{p}}-1 \mid \mathrm{k}\right)\right]^{\mathrm{T}}, \overline{\mathrm{s}}=$ $\left[\mathrm{S}_{\mathrm{d}}(\mathrm{k} \mid \mathrm{k}) \mathrm{S}_{\mathrm{d}}(\mathrm{k}+1 \mid \mathrm{k}) \mathrm{S}_{\mathrm{d}}(\mathrm{k}+2 \mid \mathrm{k}), \ldots, \mathrm{S}_{\mathrm{d}}\left(\mathrm{k}+\mathrm{N}_{\mathrm{p}}-1 \mid \mathrm{k}\right)\right]^{\mathrm{T}}$ :

$$
F=\left[\begin{array}{c}
\mathrm{CA} \\
\mathrm{CA}^{2} \\
\vdots \\
\mathrm{CA}^{\mathrm{N}_{\mathrm{p}}}
\end{array}\right]
$$

$$
\begin{gathered}
\theta=\left[\begin{array}{ccccc}
\mathrm{CB} & 0 & 0 & \cdots & 0 \\
\mathrm{CAB} & \mathrm{CB} & 0 & \cdots & 0 \\
\vdots & \vdots & \vdots & \vdots & \vdots \\
\mathrm{CA}^{\mathrm{N}_{\mathrm{p}}-1} \mathrm{~B} & \mathrm{CA}^{\mathrm{N}_{\mathrm{p}}-2} \mathrm{~B} & \mathrm{CA}^{\mathrm{Np}_{\mathrm{p}}-3} \mathrm{~B} & \cdots & \mathrm{CA}^{\mathrm{Np}_{\mathrm{p}}-\mathrm{N}_{\mathrm{C}}} \mathrm{B}
\end{array}\right] \\
\mathrm{G}=\left[\begin{array}{ccccc}
-\mathrm{C} & 0 & 0 & \cdots & 0 \\
-\mathrm{CA} & -\mathrm{C} & 0 & \cdots & 0 \\
\vdots & \vdots & \vdots & \vdots & \vdots \\
-\mathrm{CA}^{\mathrm{N}_{\mathrm{p}}-1} & -\mathrm{CA}^{\mathrm{N}_{\mathrm{p}}-2} & -\mathrm{CA}^{\mathrm{N}_{\mathrm{p}}-3} & \cdots & -\mathrm{C}
\end{array}\right]
\end{gathered}
$$


So, the objective function (8) can be written as follow:

$$
\mathrm{J}=\mathrm{Y}^{\mathrm{T}} \mathrm{QY}+\overline{\bar{u}}^{\mathrm{T}} \mathrm{R} \overline{\mathrm{l}}=2 \mathrm{u}^{\mathrm{T}} \theta^{\mathrm{T}} \mathrm{Q}[\mathrm{Fx}(\mathrm{k})+\mathrm{G} \overline{\mathrm{S}}]+2 \mathrm{u}\left[\theta^{\mathrm{T}} \mathrm{Q} \theta+\mathrm{R}\right] \overline{\mathrm{u}}
$$

where, $Q=\operatorname{diag}\left(Q_{i}\right)$ and $R=\operatorname{diag}\left(R_{i}\right)$. Based on Eq. 10-12, the constrains of the MPC design of a USV for Dubins path tracking are obtained as follow:

$$
\theta_{1} \overline{\mathrm{u}} \leq \mathrm{K}-\mathrm{Hx}(\mathrm{k})
$$

$$
\mathrm{P}_{1} \overline{\mathrm{u}} \leq \mathrm{T}_{1}
$$

$$
\mathrm{P}_{2} \overline{\mathrm{u}} \leq \mathrm{V}_{1}+\mathrm{u}_{\mathrm{b}}
$$

Where:

$$
\theta_{1}=\left[\begin{array}{ccccc}
\mathrm{C}_{1} \mathrm{~B} & 0 & 0 & \cdots & 0 \\
\mathrm{C}_{1} \mathrm{AB} & \mathrm{CB} & 0 & \cdots & 0 \\
\vdots & \vdots & \vdots & \vdots & \vdots \\
\mathrm{C}_{1} \mathrm{~A}^{\mathrm{N}_{\mathrm{P}}-1} \mathrm{~B} & \mathrm{C}_{1} \mathrm{~A}^{\mathrm{N}_{\mathrm{P}}-2} \mathrm{~B} & \mathrm{C}_{1} \mathrm{~A}^{\mathrm{N}_{\mathrm{P}}-3} \mathrm{~B} & \cdots & \mathrm{C}_{1} \mathrm{~A}^{\mathrm{N}_{\mathrm{P}}-\mathrm{N}_{\mathrm{C}}} \mathrm{B}
\end{array}\right]
$$

$$
\begin{gathered}
\mathrm{K}=\left[\begin{array}{c}
\mathrm{D}_{1} \\
\mathrm{D}_{1} \\
\vdots \\
\mathrm{D}_{1}
\end{array}\right] \\
\mathrm{H}=\left[\begin{array}{ccc}
\mathrm{C}_{1} \mathrm{~A} \\
\mathrm{C}_{1} \mathrm{~A}^{2} \\
\vdots \\
\mathrm{C}_{1} \mathrm{~A}^{\mathrm{N}_{\mathrm{P}}}
\end{array}\right] \\
\mathrm{P}_{1}=\left[\begin{array}{ccccc}
\mathrm{P} & 0 & 0 & \cdots & 0 \\
0 & \mathrm{P} & 0 & \cdots & 0 \\
0 & 0 & \mathrm{P} & \cdots & 0 \\
\vdots & \vdots & \vdots & \vdots & \vdots \\
0 & 0 & 0 & \cdots & \mathrm{P}
\end{array}\right] \\
\mathrm{P}_{2}=\left[\begin{array}{ccccc}
\mathrm{P} & 0 & 0 & \cdots & 0 \\
-\mathrm{P} & \mathrm{P} & 0 & \cdots & 0 \\
0 & -\mathrm{P} & \mathrm{P} & \cdots & 0 \\
\vdots & \vdots & \vdots & \vdots & \vdots \\
0 & 0 & 0 & -\mathrm{P} & \mathrm{P}
\end{array}\right] \\
\mathrm{T}_{1}=\left[\begin{array}{ccc}
\mathrm{T} \\
\mathrm{T} \\
\vdots \\
\mathrm{T}
\end{array}\right]
\end{gathered}
$$

$$
\mathrm{V}_{1}=\left[\begin{array}{c}
\mathrm{V} \\
\mathrm{V} \\
\vdots \\
\mathrm{V}
\end{array}\right]
$$$$
\mathrm{u}_{\mathrm{b}}=\left[\begin{array}{c}
\mathrm{u}(\mathrm{k}-1 \mid \mathrm{k}) \\
-\mathrm{u}(\mathrm{k}-1 \mid \mathrm{k}) \\
0 \\
\vdots \\
0
\end{array}\right]
$$

The optimal solution of the optimization problem in Eq. $15-18$ is denoted $\overline{\mathrm{u}}^{*}=\left[\mathrm{u}^{*}(\mathrm{k} \mid \mathrm{k}) \mathrm{u}^{*}(\mathrm{k}+1 \mid \mathrm{k}) \mathrm{u}^{*}(\mathrm{k}+2 \mid \mathrm{k}), \ldots\right.$, $\left.\mathrm{u}^{*}\left(\mathrm{k}+\mathrm{N}_{\mathrm{p}}-1 \mid \mathrm{k}\right)\right]^{\mathrm{T}}$. The input control for the system (9) is chosen from the first vector in the optimal solution, i.e.

$$
\mathrm{u}(\mathrm{k})=\mathrm{u} *(\mathrm{k} \mid \mathrm{k})
$$

Robust model predictive control for Dubins path tracking: The sea wave is assumed as the disturbance. In this study, it is assumed by first order wave disturbances. The first order wave force and moment is as follows (Fossen, 1994):

$$
\begin{gathered}
Y_{d}(t)=\sum_{i=1}^{N}-\rho g B L T \sin \beta s_{i}(t) \\
N_{d}(t)=\sum_{i=1}^{N} \frac{1}{24} \rho g B L\left(L^{2}-B^{2}\right) \sin 2 \beta s_{i}^{2}(t)
\end{gathered}
$$

Where:

$\rho=$ The density of sea water

$\mathrm{g}=$ Acceleration of gravity

$\mathrm{B}=$ Breadth of ship

$\mathrm{L}=$ Length of ship

$\mathrm{T}=\mathrm{draft}$

$\beta=$ The angle between the heading and the direction of the wave (rad)

$\mathrm{s}_{\mathrm{i}}(\mathrm{t})=$ Wave slope for wave component $\mathrm{i}$

$\mathrm{s}$ A disturbance in sway and yaw motion are obtained as follows:

$$
d_{1}(t)=M^{-1}\left[\begin{array}{c}
Y_{d} \\
N_{d}
\end{array}\right]
$$

where, $\mathrm{M}$ is matrix in Eq. 1. Therefore, the discrete form of disturbance d(k) in Eq. 9 is as follows:

$$
\mathrm{d}(\mathrm{k})=\left[\begin{array}{c}
\mathrm{d}_{1} \\
0 \\
0
\end{array}\right]
$$


The fistt step is to estimate the disturbance and can be defined as follow:

$$
\mathrm{d}(\mathrm{k})=\mathrm{d}(\mathrm{k}-1)+\epsilon
$$

where, $\epsilon$ is difference between wave at time $\mathrm{k}$ and the wave estimation at time $k-1 \epsilon \subset \mathrm{V}, \mathrm{V} \subset \mathrm{D}$ and:

$$
\widehat{d}(k-1)=x(k)-A_{d} x(k-1)-B_{d} u(k-1)+S_{d}(k-1)
$$

The additional control for disturbance compensating $\mathrm{u}_{\mathrm{d}}$ can be obtained from the optimal solution of the optimization problem II. The optimization problem II can be described as follows (Li and Sun, 2012). Minimize objective function below:

$$
\left|\mathrm{C}_{1} \mathrm{Bu}_{\mathrm{d}}+\mathrm{C}_{1} \mathrm{~d}(\mathrm{k}-1)\right|
$$

Subject to the constraints:

$$
\begin{gathered}
\mathrm{C}_{1} \mathrm{Bu}_{\mathrm{d}} \leq \mathrm{C}_{1} \hat{\mathrm{d}}(\mathrm{k}-1)-\mathrm{E} \\
\mathrm{Pu}_{\mathrm{d}} \leq \mathrm{T}
\end{gathered}
$$

Where:

$\mathrm{E}=\max \left(\mathrm{C}_{1} \varepsilon\right)=$ Furthermore, the control for disturbance compensating

$\mathrm{u}_{\mathrm{d}} \quad=$ Obtained from the objective function in Eq. 23. The control for disturbance compensating

$\mathrm{u}_{\mathrm{d}} \quad=$ will be used as a factor which influence boundary constraint of control input

$\mathrm{k} \quad=$ MPC optimization

The algorithm of robust MPS is as follows:

Estimation of the disturbance using Eq. 22

Determine the disturbance compensating control $\mathrm{u}_{\mathrm{d}}$ using Eq. 23-25

Apply MPC by considering a constraint

$\mathrm{Pu}(\mathrm{k} \mid \mathrm{k}) \leq \mathrm{T}-\mathrm{Pu}_{\mathrm{d}}$ to obtain $\mathrm{u}^{*}(\mathrm{k} \mid \mathrm{k})$.

Obtain the robust control input for system $u(k)=u^{*}(k \mid k)+u^{*}{ }_{d}$

\section{RESULTS AND DISCUSSION}

The MPC and Robust MPC simulation for the USV motion with tracking the Dubins path is considered in this section. The duration of simulation was $600 \mathrm{sec}$ with a time step of $\Delta \mathrm{t}=1 \mathrm{sec}$ was used. There are two scenarios

\begin{tabular}{|c|c|c|}
\hline Scenarios & Initial position & Final position \\
\hline 1 & $\left(0,0,0^{\circ}\right)$ & $\left(1500,1000,60^{\circ}\right)$ \\
\hline 2 & $\left(0,0,0^{\circ}\right)$ & $\left(-1500,1000,60^{\circ}\right)$ \\
\hline
\end{tabular}
in this simulation. The scenarios are shown on Table 1. There are four alternative paths from the Dubins algorithm for each scenario. Based on Tabel 2, the shortest paths are the LSL path in scenario 1 and the RSR path in
Table 2: The four alternative paths from the Dubins algorithm $\left(\times 10^{4} \mathrm{~m}\right)$

\begin{tabular}{lcccc}
\hline Scenario & RSL & RSR & LSL & LSR \\
\hline 1 & 1.6114 & 1.7119 & 1.5059 & 1.6392 \\
2 & 1.6460 & 1.5774 & 1.6405 & 1.6805 \\
\hline
\end{tabular}

\begin{tabular}{|c|c|c|c|}
\hline$\underline{\text { Scenario/ }} \mathrm{N}_{\mathrm{P}}$ & $\left\|\psi_{e}\right\|_{\text {RMSE }}$ & $\left\|\mathrm{Z}_{\mathrm{e}}\right\|_{\text {RMSE }}$ & Computational time (sec \\
\hline \multicolumn{4}{|l|}{1} \\
\hline 40 & 0.1023 & 0.0022 & 6.4270 \\
\hline 50 & 0.1007 & 0.0030 & 6.7390 \\
\hline 60 & 0.1025 & 0.0021 & 8.1750 \\
\hline \multicolumn{4}{|l|}{2} \\
\hline 40 & 0.1021 & 0.0024 & 6.7400 \\
\hline 50 & 0.1289 & 0.0085 & 7.9400 \\
\hline 60 & 0.1010 & 0.0021 & 8.5540 \\
\hline
\end{tabular}

Table 3: The computational results Dubins path tracking use MPC (No disturbance)

\begin{tabular}{llll}
\hline Scenario/ $\mathrm{N}_{\mathrm{P}}$ & $\left\|\psi_{\mathrm{e}}\right\|_{\mathrm{RMSE}}$ & $\left\|\mathrm{Z}_{\mathrm{e}}\right\|_{\text {RMSE }}$ & Computational time $(\mathrm{sec})$ \\
\hline $\mathbf{1}$ & & & \\
40 & 0.0028 & $3.8655 \times 10^{-4}$ & 6.6620 \\
50 & 0.0155 & 0.0021 & 7.0360 \\
60 & 0.001 & $1.407 \times 10^{4}$ & 7.3490 \\
$\mathbf{2}$ & & & \\
40 & 0.0181 & 0.0015 & 4.1920 \\
50 & 0.0787 & 0.0082 & 6.7390 \\
60 & 0.0122 & $5.1496 \times 10^{-4}$ & 7.8310 \\
\hline
\end{tabular}

Table 4: The computational results Dubins path tracking use MPC (with

Table 5: The computational results Dubins path tracking use MPC

\begin{tabular}{llll}
\hline Scenario/ $N_{P}$ & $\left\|\psi_{e}\right\|_{\text {RMSE }}$ & $Z_{R} \|_{\text {RMSE }}$ & Computational time (sec)
\end{tabular}
1

$40 \quad 0.0028 \quad 3.8861 \times 10^{4} \quad 12.960$

$\begin{array}{llll}50 & 0.0155 & 0.0021 & 14.072\end{array}$

$\begin{array}{llll}60 & 0.0100 & 1.4072 \times 10^{4} & 14.929\end{array}$

$\begin{array}{llll}2 & & & \\ 40 & 0.0181 & 0.0015 & 13.120\end{array}$

$\begin{array}{llll}50 & 0.0787 & 0.0085 & 14.386\end{array}$

$\begin{array}{llll}60 & 0.0122 & 5.3081 \times 10^{-4} & 14.945\end{array}$

scenario 2. The initial conditions chosen for the simulations are sway velocity $0 \times \mathrm{m} / \mathrm{sec}$, yaw velocity, $0 \times \mathrm{red} / \mathrm{sec}$, heading angle error, $0^{\circ}$, position error $0 \mathrm{~m}$. The weight matrices for the objective function of MPC are $Q_{i}$ $=\operatorname{diag}(1,1), \mathrm{i}=\operatorname{diag}(0.1)$. The matrices for constraints are $\mathrm{C}_{1}=[0,1,0,0,0,-1,0,0], \mathrm{D}_{1}[0.0932 ; 0.0932], \mathrm{P}=[1 ; 1], \mathrm{T}=$ $\left[35^{\circ} ; 35^{\circ}\right], \mathrm{V}=\left[5^{\circ} ; 5^{\circ}\right]$. The performance of MPC and robust MPC can be indicated by Root Mean Square Error (RMSE) of computational results and a computational time $(\mathrm{sec})$. The RMSE is obtained from the Equations bellow:

$$
\begin{gathered}
\left\|\psi_{\mathrm{e}}\right\|_{\text {RMSE }}=\sqrt{\frac{1}{\mathrm{Tot}} \sum_{\mathrm{i}=1}^{\text {Tot }}\left\|\psi_{\mathrm{e}}(\mathrm{i})\right\|^{2}} \\
\left\|\mathrm{Z}_{\mathrm{e}}\right\|_{\text {RMSE }}=\sqrt{\frac{1}{\mathrm{Tot}} \sum_{\mathrm{i}=1}^{\text {Tot }}\left\|\mathrm{Z}_{\mathrm{e}}(\mathrm{i})\right\|^{2}}
\end{gathered}
$$

where, Tot the number sampling steps of the simulation. $\mid \psi_{e \text { RMSE }}$ and $\mid Z_{\text {eRMSE }}$ are the RMSE of orientation and the 

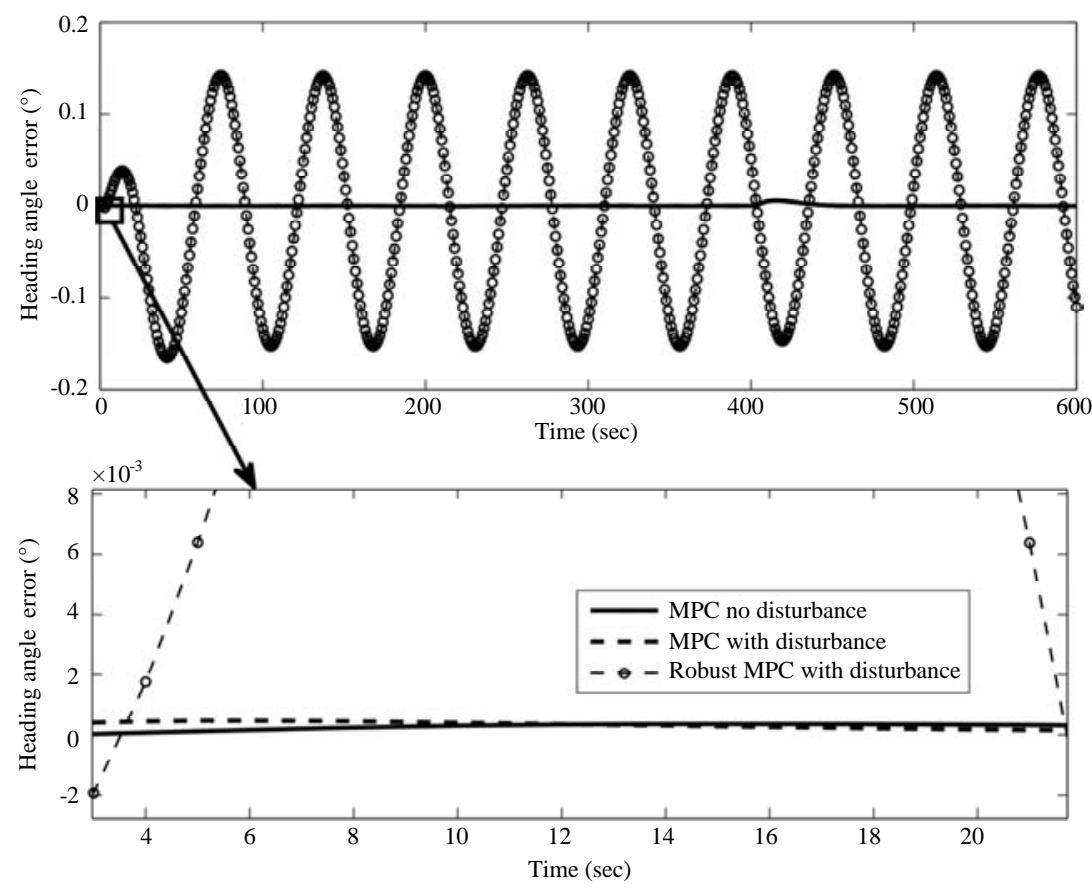

Fig. 4: The heading angle error (Scenario 1)
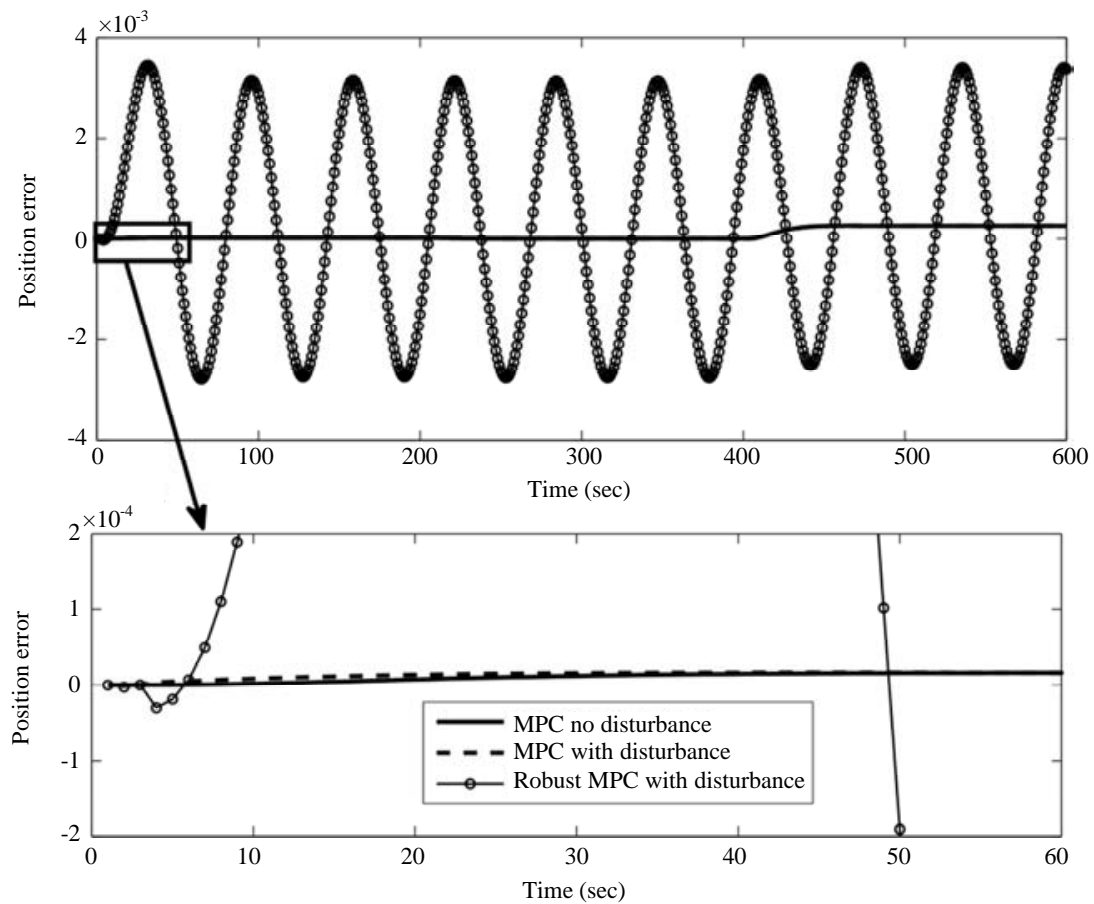

Fig. 5: The position error (Scenario 1)

RMSE of position (degree), respectively. The performances of MPC and Robust MPC with variation of the prediction horizon $\left(\mathrm{N}_{\mathrm{p}}\right)$ are shown in Table 3-4. Based on Table 3-5, the effective prediction horizon $\left(N_{\mathrm{P}}\right)$ is 60 . If there is a disturbance, MPC controller is faster than Robust MPC and RMSE of Robust MPC is smaller than RMSE of MPC. The computational results of scenario 1 which $\mathrm{N}_{\mathrm{p}} 60$ are shown in Fig. 4-6. The line graphs are 

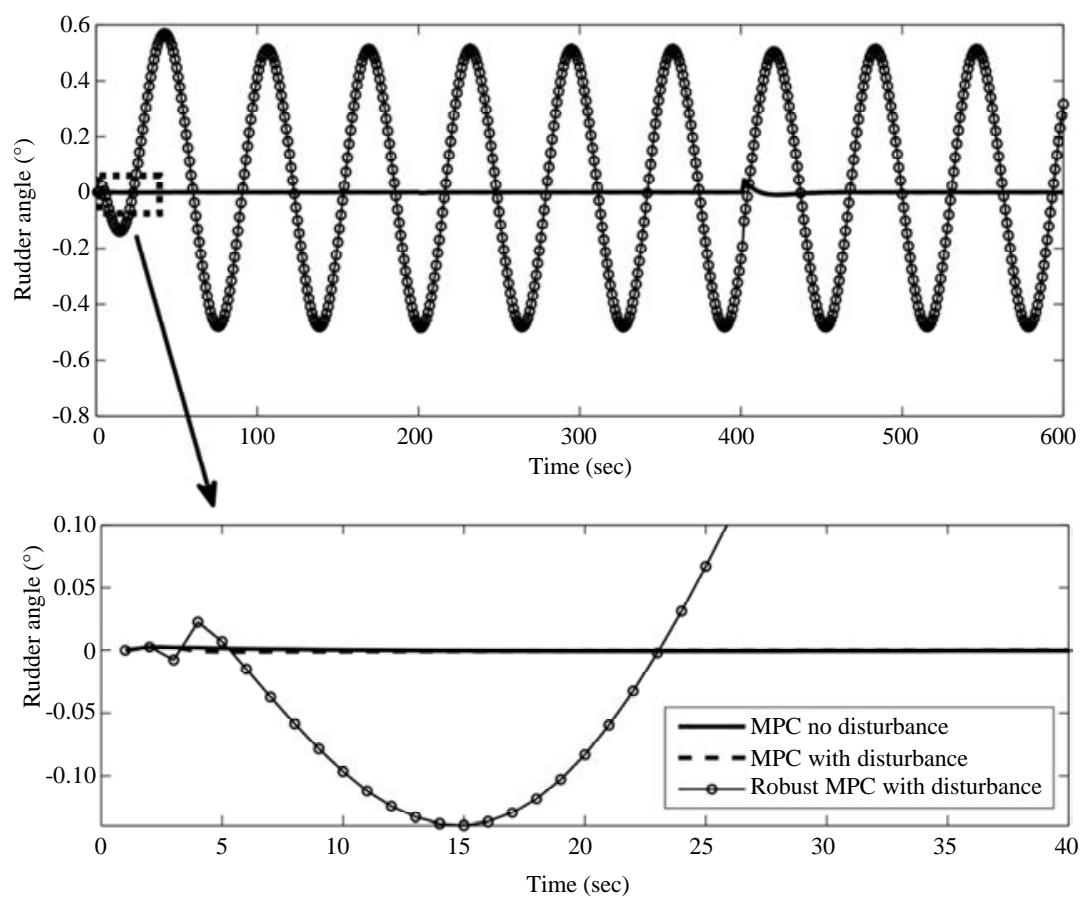

Fig. 6: The rudder angle (Scenario 1)

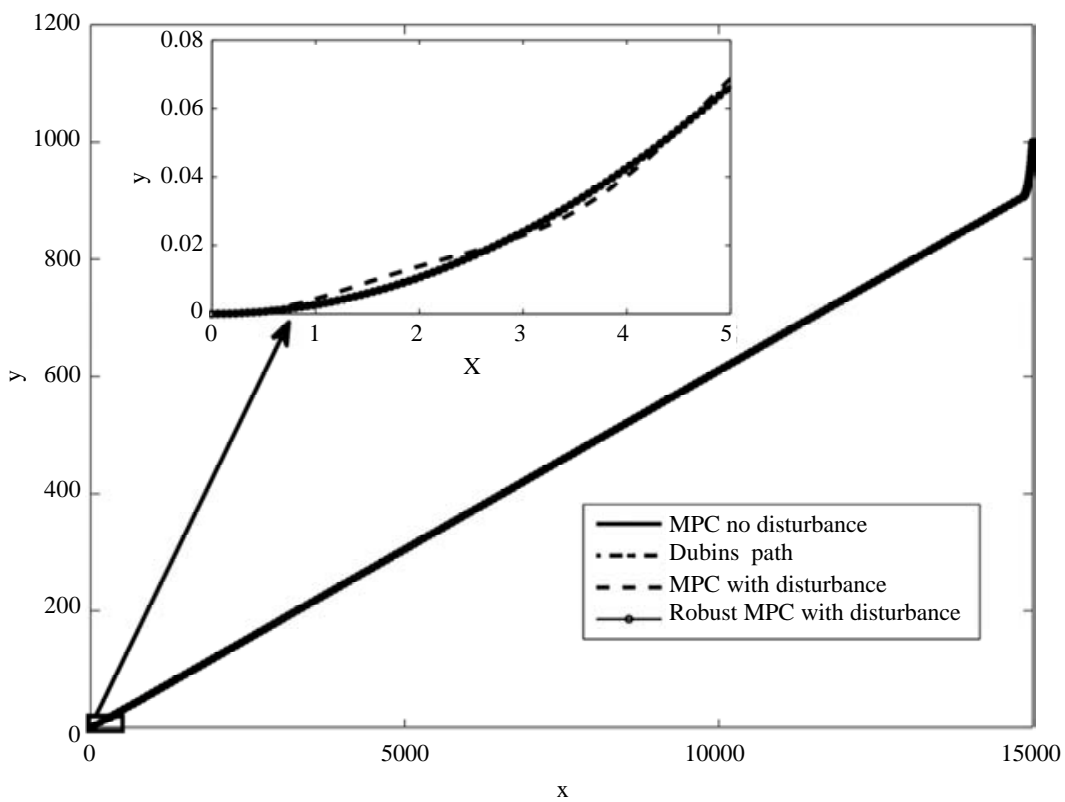

Fig. 7: Ship path (Scenario 1)

computational results of the MPC controller for system with no disturbance. The dashed line graphs are the computational results for the MPC controller of the systems with wave disturbance. The online graphs are the computational results of the robust MPC controller of the systems with wave disturbance. Based on Fig. 4-6, the robust MPC can reject a disturbance similar to the case of the MPC with no disturbance. Figure 7 shows that MPC and robust MPC can force the ship to follow the Dubins path. 


\section{CONCLUSION}

In this study, the robust MPC was designed to reject disturbance. The robust MPC has been applied to Dubins path-tracking controller on a linear model of ship motion based on error model. The Robust MPC is compared with MPC. The computational results show that the MPC and the Robust MPC can guide the ship tracking the Dubins path. The Robust MPC can reject a disturbance similar to the case of MPC with no disturbance.

\section{ACKNOWLEDGEMENT}

The researchers wish to thank DRPM RISTEKDIKTI for funding this research (No. 609/PKS/TTS/2017, April 20, 2017) and the Special Research Fund for the Doctoral Program of Higher Education of Indonesia.

\section{REFERENCES}

Asfihani, T., D. Adzkiya, D.M. Rosyid, H. Pumawan and R. Kamilah, 2017. Estimation of the corvette SIGMA motion in missile firing mission. Proceedings of the 2017 5th International Conference on Instrumentation, Control and Automation (ICA), August 9-11, 2017, IEEE, Yogyakarta, Indonesia, ISBN:978-1-5386-0350-5, pp: 203-207.

Camacho, E.F. and C. Bordons, 1999. Model Predictive Control. Springer, Berlin, Germany,

Do, K.D. and J. Pan, 2009. Control of Ships and Underwater Vehicles: Design for Underactuated and Nonlinear Marine Systems. Springer, Berlin, Germany, ISBN:978-1-84882-729-5, Pages: 400.

Dong, Z., L. Wan, Y. Li, T. Liu and G. Zhang, 2015. Trajectory tracking control of underactuated USV based on modified backstepping approach. Intl. J. Naval Archit. Ocean Eng., 7: 817-832.

Encarnacao, P. and A. Pascoal, 2001. Combined trajectory tracking and path following: An application to the coordinated control of autonomous marine craft. Proceedings of the 40th IEEE International Conference on Decision and Control (Cat. No.01 CH37228), December 4-7, 2001, IEEE, Orlando, Florida, USA., pp: 964-969.

Fossen, T.I., 1994. Guidance and Control of Ocean Vehicles. 1st Edn., Wiley, Chichester, UK., ISBN-13: 9780471941132, Pages: 494.

Fossen, T.I., 2011. Handbook of Marine Craft Hydrodynamics and Motion Control. John Wiley and Sons, Chichester.

Guerreiro, B.J., C. Silvestre, R. Cunha and A. Pascoal, 2014. Trajectory tracking nonlinear model predictive control for autonomous surface craft. IEEE. Trans. Control Syst. Technol., 22: 2160-2175.
Li, Z. and J. Sun, 2012. Disturbance compensating model predictive control with application to ship heading control. IEEE. Trans. Control Syst. Technol., 20: 257-265.

Li, Z., J. Sun and R.F. Beck, 2010. Evaluation and modification of a robust path following controller for marine surface vessels in wave fields. J. Ship Res., 54 : 141-147.

Mayne, D.Q., 2014. Model predictive control: Recent developments and future promise. Autom., 50: 2967-2986.

Peng, Y., J. Han and Z. Wu, 2007. Nonlinear backstepping design of ship steering controller: Using unscented Kalman filter to estimate the uncertain parameters. Proceedings of the 2007 IEEE International Conference on Automation and Logistics, August 18-21, 2007, IEEE, Jinan, China, ISBN:978-1-4244-1530-4, pp: 126-131.

Putri, D.K.R. and T. Asfihani, 2018. Steering angle control of car for Dubins path-tracking using model predictive control. J. Phys. Conf. Ser., 974: 012066-012066.

Qin, S.J. and T.A. Badgwell, 2003. A survey of industrial model predictive control technology. Control Eng. Pract., 11: 733-764.

Sonnenburg, C. and C.A. Woolsey, 2012. An experimental comparison of two USV trajectory tracking control laws. Proceedings of the 2012 International Conference on Oceans, October 14-19, 2012, IEEE, Hampton Roads, Virginia, USA., ISBN:978-1-4673-0829-8, pp: 1-10.

Sorbo, E.H., 2013. Vehicle collision avoidance system. Master Thesis, Norwegian University of Science and Technology, Trondheim, Norway.

Subchan, S. and R. Zbikowski, 2009. Computational Optimal Control: Tools and Practice. John Wiley \& Sons, Hoboken, New Jersey, ISBN:978-0-470-71440-9, Pages: 179.

Subchan, S., B.A. White, A. Tsourdos, M. Shanmugavel and R. Zbikowski, 2008. Dubins path planning of multiple UAVs for tracking contaminant cloud. Proceedings of the 17th International World Congress on Federation of Automatic Control Seoul Vol. 41, July 6-11, 2008, Korea, pp: 5718-5723.

Subchan, S., W.H. Syaifudin and T. Asfihani, 2014. Ship heading control of corvette-sigma with disturbances using model predictive control. Far East J. Appl. Math., 87: 245-256. 
Sulisetyono, A. and T. Putranto, 2017. Wave load analysis of the corvette ship in the sea water of Indonesia. Appl. Mech. Mater., 862: 291-295.

Tsourdos, A., B. White and M. Shanmugavel, 2010. Cooperative Path Planning of Unmanned Aerial Vehicles. Vol. 32, John Wiley \& Sons, Hoboken, New Jersey, USA., ISBN:978-0-470-74129-0, Pages: 187.

Wang, X., B. Zhang, D. Chu and H. Wang, 2011. Adaptive analytic model predictive controller for path following of underactuated ships. Proceedings of the 2011 30th International Conference on Chinese Control (CCC), July 22-24, 2011, IEEE, Yantai, China, ISBN:978-1-4577-0677-6, pp: 5515-5521.
Yin, S. and B. Xiao, 2017. Tracking control of surface ships with disturbance and uncertainties rejection capability. IEEE/ASME Trans. Mechatron., 22: 1154-1162.

Zheng, H., R.R. Negenborn and G. Lodewijks, 2014. Trajectory tracking of autonomous vessels using model predictive control. Proceedings of the 19th International World Congress on Federation of Automatic Control Cape Town Vol. 47, August 24-29, 2014, South Africa, pp: 8812-8818.

Zheng, Y., Z. Liu and L. Liu, 2018. Robust MPC-based fault-tolerant control for trajectory tracking of surface vessel. IEEE. Access, 6: 14755-14763. 